\title{
Alegorias del franquismo. Narciso Ibáñez Serrador y las Historias para no dormir (1966-1982)
}

\section{Sofía Otero-Escudero}

Universidad de Sevilla sofoteesc@gmail.com https://orcid.org/0000-0003-0778-1519

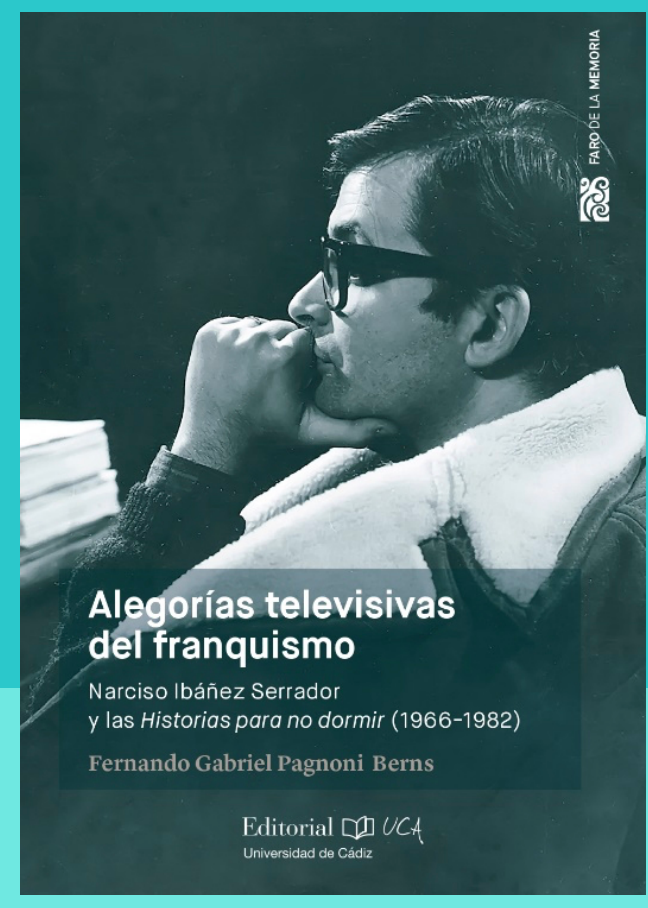

Fernando Gabriel Pagnoni Berns Universidad de Cádiz Cádiz, España, 2019 240 páginas 
En las vísperas del 20 de noviembre de 2021 una serie de noticias se disparan en torno a la prevención de conmemoraciones en España por el fallecimiento de Francisco Franco; eventos que conllevan la exaltación del franquismo y, por lo tanto, atentan contra la dignidad de las víctimas de la dictadura. En el libro Alegorías del franquismo. Narciso Ibáñez Serrador y las Historias para no dormir (1966-1982), Fernando Gabriel Pagnoni Berns comienza el texto señalando su sorpresa al llegar a Madrid un 20 de noviembre de 2016 y encontrar un grupo de personas -la mayoría jóvenes- que conmemoraban la muerte de Francisco Franco el 20 de noviembre de 1975. Esta situación que se perpetúa en el presente es una evidencia viva del eje vertebrador de la obra del doctor en Historia y Teoría de las Artes. El espectro del franquismo continúa vagando por las calles de la España contemporánea, dejando un rastro indiscutible de la historia del país que está todavía latente. Esta aparente anacronía, al encontrar una reunión de personas que conmemoran el fallecimiento del dictador es una de las piezas claves en la obra de Fernando Gabriel que, siguiendo la teoría de Didi-Huberman sobre el estudio de la historia "a contrapelo", se aleja del historicismo que analiza lo acontecido solo desde las circunstancias que lo rodearon y lo observa desde la perspectiva de la actualidad. Así, el autor desarrolla de forma sobresaliente un estudio "a contrapelo" de las inolvidables Historias para no dormir (1966-1982) de Narciso Ibáñez Serrador; serie de televisión que, además, ha sido re-adaptada en 2021 a través de cuatro episodios para la plataforma Amazon Prime, reafirmando y materializando de este modo el valor de la serie reseñada por Pagnoni, así como su tesis que afirma que la historia siempre sigue presente, no como un fantasma que atemoriza, sino como un espectro que sutilmente permea todo lo presente: “¿Es una alegoría? Es como una llamada a la tierra, como quedarse con lo importante, ¿no? como volver a lo básico, como un grito de socorro", le espeta una niña al protagonista del episodio contemporáneo de El asfalto (Ortiz, 2021), explicitando dentro de la propia historia la relevancia de lo alegórico y su inmutabilidad, así como jugando con una intertextualidad obvia donde la obra de Pagnoni se erige como pieza de inestimable valor.

Para el estudio de esta serie tan analizada, visionada y re-adaptada, el investigador desarrolla una perspectiva genuina reseñando la función alegórica de los episodios que conforman la serie de televisión española y que, en sus propias palabras, funcionan como: "fuente de memoria alegórica que revela la violencia cotidiana ya naturalizada en los años sesenta" (p.29).

Desde la introducción, atrapa al lector con una redacción impecable y de gran interés divulgativo para, posteriormente, entrar de lleno en una breve contextualización sobre el franquismo, la cual se aleja de los datos más canónicos y comúnmente conocidos, construyendo los pilares necesarios para sostener el resto de la obra y dejar que fluya sin ningún tipo de complicación. Los datos referidos se ven teñidos de forma intencionada con el espectro siempre presente de su teoría sobre el terror y las alegorías como sublimación del contexto de opresión y alineación que constituía la dictadura franquista, haciendo hincapié en el rol de los medios, la cultura y el arte, tanto como disciplinas subversivas por su valor educativo y revolucionario, como oprimidas por la misma razón. Al igual que Ibañez Serrador combinaba con el terror otros géneros como el suspense, la fantasía e incluso la comedia, Pagnoni hibrida de forma exquisita con la televisión las distintas disciplinas artísticas, como el teatro o la literatura -las Historias para no dormir también eran en su mayoría adaptaciones de relatos-. 
Posteriormente a la contextualización histórica y el breve repaso por el género de terror español, el autor comienza su travesía por la serie Historias para no dormir con el primer capítulo de la teleserie «El cumpleaños». De este modo, continúa de forma cronológica su recorrido por las obras de Narciso Ibañez Serrador hasta el capítulo cuarto, donde cierra la teleserie con su último episodio de la segunda temporada «El asfalto», junto a una profunda reflexión sobre la asfixia de la ciudadanía, así como el individualismo patológico inculcado por el sistema capitalista. Para la descripción de cada capítulo de Historias para no dormir, Pagnoni los integra en el texto de forma impecable, definiendo al detalle y de modo muy visual los episodios junto a su significado alegórico en relación con el contexto. Ya en el epígrafe cinco, último antes de las conclusiones, aborda el salto a la gran pantalla de Ibañez Serrador tras la muerte de Francisco Franco y la reaparición del realizador en televisión con la tercera temporada de Historias para no dormir en 1982. De este modo, en lugar de desarrollar un listado de episodios descritos, el autor los integra en capítulos donde aborda diversos aspectos de la sociedad durante el franquismo, así como el género de terror y fantástico, haciendo que la lectura discurra de forma amena y fluida.

El docente e investigador acierta al poner el foco en la serie mencionada para ensalzar el valor del damnificado género de terror español y, al mismo tiempo, dejar sobre la mesa una reflexión cautivadora sobre el subtexto de las historias que Narciso Ibañez Serrador narraba los viernes por la noche para la audiencia de TVE. Unas historias que, como bien destaca el escritor, no solo no dejaban dormir a la audiencia por el terror infundido, sino porque buscaban el insomnio más esclarecedor que incita a pensar, el que despierta a las masas. Según el autor, el género de terror era utilizado con finalidad escapista, aunque en el caso de Ibañez Serrador esta vía de escape era doble y también llevaba a reflexionar a través de la alegoría sobre el contexto de opresión que vivía la sociedad. Dicha reflexión se basa en la premisa establecida por el investigador que afirma que la teleserie "puede entenderse y leerse hoy como un espejo deformante en el cual se reflejan gran parte de la sociedad española bajo el gobierno de Francisco Franco" (p.23); espejo deformante que, además, convierte en monstruosas a ciertas identidades, acertadamente denominadas como "otredades" y referidas por Pagnoni como aquellas que se salen de lo normativo y subvierten lo establecido, señalando la sexualidad femenina o la homosexualidad, entre otras. Este aspecto evidencia la perspectiva de género e inclusiva del investigador, no solo como contextualización sobre aquello que fue relegado a los márgenes durante el franquismo, sino integrándolo en su propio estudio y redacción. Dentro de esta "otredad", uno de los conceptos más pertinentes para el tema de estudio es la figura del monstruo, la cual en diferentes estudios de género, en particular del colectivo trans, es mencionado en diversas ocasiones para hacer referencia a aquello que se sale de la norma y que, para discriminarlo, se designa como monstruoso dado que "su faceta más siniestra proviene de su capacidad de poner en duda los límites de la propia existencia humana, convirtiéndose en una figura abyecta" (Clúa, 2007, p.187).

Además de la transversalidad de esta perspectiva, se añade en el texto un capítulo específico dedicado exclusivamente a esbozar el rol de la mujer durante el tardofranquismo, incluyendo para ello el análisis de diversos episodios de Historias para no dormir, como son «El doble» o «La cabaña». Del mismo modo, se hace hincapié en la infancia como sector donde recaía la esperanza de despertar del letargo, así como el temor de volver a recaer en la misma violencia 
y alienación que sus padres y madres vivieron. Tal y como dijo Fernando Fernán Gómez en la película La lengua de las mariposas: "de algo estoy seguro: si conseguimos que una generación, una sola generación, crezca libre en España, ya nadie les podrá arrancar nunca la libertad. Nadie les podrá robar ese tesoro" (Cuerda, 1999). Con este foco en la infancia, Pagnoni engarza con el desenlace del texto saltando de la serie de televisión a la gran pantalla, tal y como hizo Ibañez Serrador al estrenar su filme más crítico con los medios de comunicación -El televisor (Ibañez, 1974) - y, a continuación, ¿Quién puede matar a un niño? (Ibañez, 1976), escrita en 1975 pero estrenada posteriormente al fallecimiento del dictador en 1976. Junto a estos filmes, destaca la adaptación de uno de los episodios de la teleserie a la película La culpa (Ibáñez, 2006), junto a una ecuánime crítica sobre el conservadurismo de esta y el alejamiento de la alegoría que buscaba hacer pensar.

Para terminar el libro y siguiendo una construcción circular, Pagnoni Berns concluye con un acontecimiento real. Al igual que al comienzo narra su experiencia al encontrar la conmemoración del 20 de noviembre de 2016 en Madrid, en las conclusiones cierra con la mención a la exhumación de los restos de Franco en 2019, así como todo el debate y revuelo generado, evidenciando el valor de su libro como obra atemporal y siempre pertinente, que retrotrae al pasado, sin perder de vista el presente.

\section{Referencias}

Clúa, I. (2007). Género, cuerpo y performatividad, en Meri Torras (ed.), Cuerpo e identidad. Estudios de género y sexualidad I (pp.41-54). Barcelona: Edicions UAB.

Cuerda, J.L. (1999). La lengua de las mariposas. Sogetel, Las Producciones del Escorpión, Canal+ España, TVE.

Ibañez Serrador, N. (1966-1982). Historias para no dormir. TVE.

Ibañez Serrador, N. (1974). El televisor. TVE.

Ibañez Serrador, N. (1976). ¿Quién puede matar a un niño? Penta Films.

Ibañez Serrador, N. (2006). La culpa. Filmax.

Ortiz, P. (2021). El asfalto. VIS, Prointel, Isla Audiovisual.

Pagnoni Berns, F.G. (2019). Alegorías televisivas del franquismo. Narciso Ibañez Serrador y las Historias para no dormir (1966-1982). Cádiz: Editorial UCA. 